\title{
Social work support and unmet social needs in life after stroke: a cross-sectional exploratory study
}

Sophie Lehnerer ${ }^{1,2,3^{*}}$ (D), Benjamin Hotter ${ }^{1,2,3}$, Inken Padberg $^{1,4}$, Petra Knispel ${ }^{1,5}$, Dike Remstedt ${ }^{3}$, Andrea Liebenau', Ulrike Grittner ${ }^{6,7}$, lan Wellwood ${ }^{8}$, Andreas Meisel ${ }^{1,2,3,5}$ and on behalf of the BSA Long Term Care Study Group

\begin{abstract}
Background: Stroke patients are often affected by long-term disabilities with needs concerning social issues. There is relatively little consideration of social recovery of patients and the support required to return to work, receive social benefits, participate in daily life activities, maintain contact with family and friends and to organize financial affairs. In our study we aimed to investigate if existing tools record social needs adequately. We analyzed the current provision of social support provided in long-term care after stroke and whether unmet social needs were associated with quality of life, caregiver burden, overall function and degree of disability.
\end{abstract}

Methods: Our analysis is part of the Managing Aftercare of Stroke study (MAS-I), a cross-sectional exploratory study of patient needs 2-3 years after initial stroke. Assessment tools included the Nikolaus-score (social situation), the EuroQoL (quality of life), the German Burden Scale for Family Caregivers (caregiver burden), the modified Rankin Scale (disability / dependence), Stroke Impact Scale (function and degree of disability) and the Stroke Survivor Needs Questionnaire (unmet needs).

Results: Overall 57 patients were included in MAS-I, with ten patients classified in urgent need of socio-economic support according to the Nikolaus-score. Patients with lower than normal Nikolaus-score had a higher degree of disability. Thirty percent of all patients had never received professional social support. Social worker contact happened mostly during the stay in acute hospital or rehabilitation institution. Only four patients (11\%) reported long-term support after discharge. Apart from social worker contact during acute care, $43 \%$ of patients had unmet needs in the long-term aftercare. Forty percent of all patients included in MAS-I were recommended for social work intervention after an in-depth analysis of their situation. Finally, we saw that unmet social needs were associated with lower quality of life and higher caregiver burden.

Conclusions: Our data suggest significant unmet needs in social care in long-term stroke patients. Screening tools for unmet social needs such as the Nikolaus-score do not holistically report patients' needs.

Trial registration: Clinicaltrials.Gov NCT02320994. Registered 19 December 2014 (retrospectively registered).

Keywords: Stroke, Long-term care, Social situation, Unmet social needs, Assessment tools, Screening social work

\footnotetext{
* Correspondence: sophie.lehnerer@charite.de

${ }^{1}$ Center for Stroke Research Berlin, Charité University Medicine Berlin,

Charitéplatz 1, 10117 Berlin, Germany

${ }^{2}$ Department of Neurology, Charité University Medicine Berlin, Charitéplatz 1,

10117 Berlin, Germany

Full list of author information is available at the end of the article
}

(c) The Author(s). 2019 Open Access This article is distributed under the terms of the Creative Commons Attribution 4.0 International License (http://creativecommons.org/licenses/by/4.0/), which permits unrestricted use, distribution, and reproduction in any medium, provided you give appropriate credit to the original author(s) and the source, provide a link to the Creative Commons license, and indicate if changes were made. The Creative Commons Public Domain Dedication waiver (http://creativecommons.org/publicdomain/zero/1.0/) applies to the data made available in this article, unless otherwise stated. 


\section{Background}

Stroke patients are often affected by long-term disabilities with complex needs requiring a combination of medical, nursing, therapeutic and social interventions to address a wide range of concurrent symptoms such as paresis, spasticity, pain, aphasia, cognitive impairment and depression [1-3]. Several approaches have been proposed to provide comprehensive assistance to patients after stroke $[4,5]$, however, many focus on promoting early return to the community rather than on-going care [6-13].

For post-stroke impairments like sensory-motor dysfunction or aphasia as well as for post-stroke comorbidities such as spasticity, pain, cognitive impairment and depression, clinical guidelines [10] and some therapeutic treatment options are available [14-20]. On the other hand, there is relatively little attention to the social recovery of patients. Support for social recovery may include professional support to return to work, access social benefits, participate in activities of daily life, maintain contact with family and friends and organize financial affairs [21-23]. According to the "Burden of stroke in Europe" report there is a lack of long-term support (that we term "aftercare") for stroke in every European country [24]. There are some studies focussing on specific issues or patients' experiences [25], but few have aimed to achieve a holistic view of the social situation in long-term aftercare of stroke patients [22] and its interdependency with post-stroke sequelae.

Here we aimed to investigate if existing tools like the Nikolaus-score [26] and the Stroke Survivor Needs questionnaire [27] record unmet social needs adequately, and what kind of additional information is relevant. This includes unmet needs which are likely to occur, but which cannot be addressed at time of assessment.

Furthermore, we aimed to evaluate the current provision of social support provided in long-term care after stroke and the prevalence of unmet social needs in the long-term and whether these unmet needs were associated with quality of life (EuroQoL (EQ-5D-3 L) [28]), the caregiver burden (Häusliche Pflegeskala, HPS-k [29]), the overall function and degree of disability (modified Rankin Scale (mRS) [30] and the Stroke Impact Scale [31].

\section{Methods}

\section{Study-design}

The present exploratory analysis is part of the MAS-Istudy, a cross-sectional exploratory study of post rehabilitation patient needs and caregiver burden after stroke [11]. The dataset represents a first step in a more complex project, aiming to gather information on unmet medical and social needs in the long-term aftercare for stroke in the outpatient setting. Briefly, stroke patients from two previous acute clinical studies were invited 23 years after the initial event to attend the outpatient department for a comprehensive interview and examination carried out by a trained neurologist and social worker using validated standard measures of selfreported needs, quality of life, overall outcome, spasticity, pain, aphasia, cognition, depression, secondary prevention, social needs and caregiver burden [11]. No financial incentive was provided, but transport was organized and paid for, if necessary. Written consent was given before participation; details are provided in the section "Declarations". The study received ethics committee and data protection approval by the institutional review board of Charité University Medicine, Berlin (reference EA1/183/14) and was registered on clinicaltrials.gov (NCT02320994).

\section{Scores}

In the current study we explored the patients' contact with social workers, assessed by self-reported previous support and its association with the social situation assessed with the German Nikolaus-score [26] (unmet social needs are indicated by sum score values of 17 or below, ranges from 0 to 25 (no unmet social needs), see Additional file 2 for an unofficial translation by the authors). Furthermore, we explored the quality of life assessed with the EuroQoL (EQ-5D-3 L, index ranges from 0 (poor quality of life) to 1) [28], the caregiver burden with the German Burden Scale for Family Caregivers (Häusliche Pflegeskala, HPS-k, ranges from 0 to 30 (high caregiver burden)) [29], the overall function and degree of disability (modified Rankin Scale (mRS), ranges from 0 (no symptoms) to 6 (death) [30] and one item (item 8 - participation in activities of daily living) from the Stroke Impact Scale [31]. To explore the scope and content of the tools we also assessed the patients using components of the Stroke Survivor Needs questionnaire [27]. This questionnaire does not work as a score, but contains additional information not provided by the Nikolaus-score, with fourteen questions inquiring about unmet social needs like need for help in the household and personal care, in managing finances and applying for social benefits (listing of the fourteen items and dividing into seven domains see Table 1). Furthermore, the validated scales were integrated in the interview and conversation between social worker and patient. We recorded standardized individual recommendations issued by a stroke neurologist and social worker after an in-depth analysis of the current care according to national and international clinical guidelines [10]. We used these recommendations as a surrogate measure of current gaps in the ongoing care of these patients. If unmet social needs were identified, the patient received a recommendation for further social work 
Table 1 Unmet social needs (Nikolaus-score), recommendation of social work intervention and in-detail analyses of the Stroke Survivor Nneeds questionnaire

\begin{tabular}{|c|c|c|c|}
\hline ID (patients) & $\begin{array}{l}\text { Unmet social needs } \\
(<17 \text { points in the Nikolaus-score) }\end{array}$ & Social work intervention recommended & $\begin{array}{l}\text { Number of unmet needs in defined items of } \\
\text { the Stroke Survivor Needs questionnaire (domain }{ }^{1} \text { ) }\end{array}$ \\
\hline 1 & yes & yes & $6(A, 2 \times B, C, D, F)$ \\
\hline 2 & yes & yes & $1(\mathrm{C})$ \\
\hline 3 & yes & yes & $4(A, B, D)$ \\
\hline 4 & yes & yes & $2(A, C)$ \\
\hline 5 & yes & yes & $6(A, 2 \times C, D, 2 \times G)$ \\
\hline 6 & yes & yes & $2(F, G)$ \\
\hline 7 & yes & yes & $3(D, F, G)$ \\
\hline 8 & yes & yes & $2(D, F)$ \\
\hline 9 & yes & yes & 0 \\
\hline 10 & yes & Data missing & $2(C, F)$ \\
\hline 11 & no & yes & $2(2 \times C)$ \\
\hline 12 & no & yes & $1(\mathrm{D})$ \\
\hline 13 & no & yes & $1(\mathrm{~A})$ \\
\hline 14 & no & yes & $4(A, C, F, G)$ \\
\hline 15 & no & yes & $4(2 \times C, F, G)$ \\
\hline 16 & no & yes & $1(\mathrm{D})$ \\
\hline 17 & no & yes & 0 \\
\hline 18 & no & yes & $3(A, 2 \times C)$ \\
\hline 19 & no & yes & $2(A, E)$ \\
\hline 20 & no & yes & $2(A, F)$ \\
\hline 21 & no & yes & $1(\mathrm{G})$ \\
\hline 22 & no & yes & $2(F, G)$ \\
\hline 23 & no & Data missing & $1(\mathrm{~A})$ \\
\hline 24 & no & Data missing & $2(C, F)$ \\
\hline 25 & no & Data missing & 0 \\
\hline 26 & no & no & $1(\mathrm{~F})$ \\
\hline 27 & no & no & $1(\mathrm{~A})$ \\
\hline 28 & no & no & $2(2 \times C)$ \\
\hline 29 & no & no & $1(\mathrm{~A})$ \\
\hline 30 & no & no & $1(B)$ \\
\hline 31 & no & no & $4(A, 2 x C, E)$ \\
\hline 32 & no & no & $1(\mathrm{~F})$ \\
\hline 33 & no & no & $3(A, C, F)$ \\
\hline 34 & no & no & $1(\mathrm{G})$ \\
\hline 35 & no & no & $1(\mathrm{~F})$ \\
\hline 36 & no & no & $1(\mathrm{~F})$ \\
\hline 37 & no & no & $2(C, F)$ \\
\hline 38 & no & no & $1(A)$ \\
\hline 39 & no & no & $3(2 \times D, F)$ \\
\hline 40 & no & no & $3(A, C, F)$ \\
\hline 41 & no & no & $1(\mathrm{~A})$ \\
\hline 42 & no & no & $1(\mathrm{E})$ \\
\hline 43 & no & no & $1(\mathrm{~A})$ \\
\hline
\end{tabular}


Table 1 Unmet social needs (Nikolaus-score), recommendation of social work intervention and in-detail analyses of the Stroke Survivor Nneeds questionnaire (Continued)

\begin{tabular}{llll}
\hline ID (patients) & $\begin{array}{l}\text { Unmet social needs } \\
(<17 \text { points in the Nikolaus-score) }\end{array}$ & Social work intervention recommended & $\begin{array}{l}\text { Number of unmet needs in defined items of } \\
\left.\text { the Stroke Survivor Needs questionnaire (domain }{ }^{1}\right)\end{array}$ \\
\hline 44 & no & no & $1(\mathrm{~A})$ \\
45 & no & no & $2(\mathrm{C}, \mathrm{F})$ \\
46 & no & no & $3(2 \times \mathrm{C}, \mathrm{F})$ \\
47 & no & no & $2(\mathrm{~A}, \mathrm{~B})$ \\
48 & no & no & 4 (A, B, D, E) \\
49 & no & no & 1 (A) \\
50 & no & no & $2(\mathrm{~A}, \mathrm{D})$ \\
51 & no & no & 0 \\
52 & no & no & 0 \\
53 & no & no & 0 \\
54 & no & no & 0 \\
55 & no & no & 0 \\
56 & no & no & 0 \\
57 & no & no & 0
\end{tabular}

${ }^{1}$ Domain (Number of item in the stroke survivor needs questionnaire [27])

$A=$ more information about stroke required [1]

$B=$ personal care or professional help for household required $[17,18]$

$C=$ further equipment, adaptions outside the home or moving home required [19-21]

$\mathrm{D}=$ advice about driving after stroke or travelling with public transport required $[23,24]$

$\mathrm{E}=$ advice about physical relationships with partner required [29]

$\mathrm{F}=$ access to a support group required [32]

$\mathrm{G}=$ information about application for social benefits, managing finances and re-employment required [36-39]

intervention which was performed in the stroke service point of the Berlin Stroke Alliance [32]. This intervention however, did not form part of the study. Recommended social work interventions address non-medical needs in primary health care [33]. This includes access to out-patient nursing care (including general home care, palliative care, family care and short term home care), home adaptation and aids (including changes around the house, emergency house calls and other aids at home), help with mobility and transport (including driving services for recreation or provision of companions for people with decreased mobility). Furthermore social work intervention implies the provision of information about out-patient and in-patient rehabilitation and help with applications for benefits (specific to the German health care system) [34].

Relevant licences were obtained for scores which were not available licence-free.

\section{Statistical analysis}

Statistics were calculated using SPSS 24.0 software (IBM, Armonk, NY). Standard descriptive statistics were chosen depending on the scaling and distribution of the variables. Associations between the assessments were calculated using Pearson's $X^{2}$ and Mann-Whitney U depending on the scaling of the variables as specified in detail in the result Tables. A two-sided significance level of $\alpha=0.05$ was considered. No adjustment for multiple testing was applied in this exploratory study.

\section{Results}

Unmet social needs and recommendation of social work intervention

Overall 57 patients were included in MAS-I [11]. As Table 1 shows, all patients were assessed for social needs using the Nikolaus-score with 10 patients needing socioeconomic support according to the score results. Of these patients, nine received the recommendation to be supported by a social work intervention due to low Nikolaus-score. Another twelve patients, although with Nikolaus-score values higher than the cut-off value of 17 points, were referred to a social worker intervention. This is because the recommendations for social work intervention made by the clinician were not only based on the Nikolaus-score, but also on the interview by the social worker that included questions on the stroke survivor's needs. The additional information provided by the patient while answering the questionnaire and the informal check of the social worker whether preconditions for social benefits were given, were the trigger to recommend social work intervention. The above mentioned 12 patients in Table 1 expressed unmet needs in the domain "information about application for social benefits, managing finances and reemployment 
required". Twenty-four patients were not referred to a social worker, although they showed needs in the questions from the Stroke Survivor Needs questionnaire. These needs are not currently covered under the legal entitlements in Germany, unless individual preconditions have been met and some elements of care may not be covered by nursing care or personal care insurance.

\section{Characteristics of patients with unmet social needs}

While age and sex (see Table 2) was similarly distributed in patients with values above and below 17 points in the Nikolaus-score (median 19), the degree of disability and dependence in daily activities according to the modified Rankin Scale was higher in patients with less than 17 points in the Nikolaus-score (median 3 vs. $2, p=0.018$ ). Patients with low Nikolaus-score $(<17$ points) furthermore reported a more accentuated negative impact of stroke on their life (Stroke Impact Scale, median 21 vs. $34, p=0.002)$, and a lower quality of life (EQ-5D-3 L index value, 0.70 vs. $0.89, p=0.02$ ) (all see Table 2). In addition, the nearest relatives of the patients with low Nikolaus-scores $(<17$ points) reported a higher caregiver burden (HPS-k, median 21 vs. 6, $p=0.053$, Table 2) compared to caregivers of patients with higher Nikolausscores. Nikolaus-score was positively associated with net income (Spearman $r=0.39, p=0.008$ ), with a mean net income of $€ 1300$ Euro in patients below 17 points versus $€ 2225$ Euro in patients with higher score values in the Nikolaus-score (Table 2), signifying more unmet social needs in patients with a higher economic strain.

Accordingly, patients receiving a recommendation for intervention by a social worker were more severely affected by their stroke (median mRS 3 vs. $1, p=0.13$, median Stroke-Impact-Scale 24 vs. 34, $p=0.014$, Table 3). Thus, more severely affected patients $(\mathrm{mRS}>2)$ had a lower Nikolaus-score (median 19 vs. 21, $p=0.013$ ) and more often received recommendations for social work interventions ( $57 \%$ vs. $28 \%, p=0.035$, Table 4 ) compared to less affected patients.

\section{Contact with social workers in the aftercare of stroke}

During the interviews, all patients were questioned about previous contact with social workers. Table 5 shows, that seventeen patients (30\%) had never received professional social support. If social support was provided, the consultation happened mostly during the stay in acute hospital or neuro-rehabilitation institution (37 of 39 patients, see Additional file 1$)$. Only $11 \%(n=4 / 36)$ reported long-term support after discharge, and $61 \%(n=$ 22/36) have not been informed in-detail about their situation and perspectives (for missings, detailed content and quality of social support see Table 6). Patients who received neuro-rehabilitation treatment $(n=45 / 55)$ were more likely to be contacted by a social worker than patients without neuro-rehabilitation treatment (35/45 [78\%] vs. $1 / 10[10 \%], p<0.001$, additional results without table).

Patients who received social support were more severely affected by stroke than patients not receiving social support (median mRS 2 vs. $1, p=0.058$, Table 5). In 16 out of 37 (43\%) patients who had contact with social workers, further social work intervention was recommended during the stay in the acute hospital or rehabilitation center due to unmet social needs. Table 5 shows that average age, sex distribution, years of education and net income were similar in patients receiving social support or not. We did not see pronounced differences in the prevalence of unmet needs between patients with or without previous contact with social workers.

\section{Discussion}

One third of all patients included in the MAS-I study reported having had no contact with social workers. Possibly, contact with social workers in the acute phase of stroke was not always recognized, perhaps because of

Table $\mathbf{2}$ Characteristics of patients with unmet social needs (Nikolaus-score)

\begin{tabular}{|c|c|c|c|c|}
\hline & Total $(n=57)$ & $\begin{array}{l}\text { Urgent need of social help } \\
\text { (Nikolaus-score }<17)(n=10)\end{array}$ & $\begin{array}{l}\text { No urgent need of social help } \\
\text { (Nikolaus-score }>16)(n=47)\end{array}$ & $p$-value \\
\hline Age, mean (SD) & $70(10)(n=55)$ & $68(12)(n=10)$ & $71(9)(n=45)$ & $0.623^{a}$ \\
\hline Male, n (\%) & $33(58 \%)(n=57)$ & $4(40 \%)(n=10)$ & $29(62 \%)(n=47)$ & $0.207^{b}$ \\
\hline \multicolumn{5}{|l|}{ Scores at MAS visit } \\
\hline Nikolaus-score median (IQR) & $19(17-22)(n=57)$ & $14(12-16)(n=10)$ & $20(19-22)(n=47)$ & \\
\hline Modified Rankin Scale (mRS) median (IQR) & $2(1-3)(n=57)$ & $3(2-4)(n=10)$ & $2(1-3)(n=47)$ & $0.018^{a}$ \\
\hline Stroke-Impact-Scale median (IQR) & $32(23-40)(n=57)$ & $21(18-25)(n=10)$ & $34(26-40)(n=47)$ & $0.002^{a}$ \\
\hline EQ-5D-5 L-Index median (IQR) & $0.81(0.70-1.00)(n=57)$ & $0.70(0.38-0.79)(n=10)$ & $0.89(0.70-1.00)(n=47)$ & $0.020^{a}$ \\
\hline Caregiver burden scale (HPS-k) median (IQR) & $6(1-11)\left(n=24^{\circ}\right)$ & 21 (values: 6; 27) $(n=3)$ & $6(1-9)(n=21)$ & $0.053^{a}$ \\
\hline Years of education Median (IQR) & $14(12-17)(n=56)$ & $14(12-17)(n=10)$ & $14(12-17)(n=46)$ & $0.957^{\mathrm{a}}$ \\
\hline Net income in Euro median (IQR) & $2200(1200-2500)(n=47)$ & $1300(516-2500)(n=9)$ & $2225(1425-2550)(n=38)$ & $0.170^{a}$ \\
\hline
\end{tabular}

${ }^{\mathrm{a}}$ Mann-Whitney-U Test, ${ }^{\mathrm{b}}$ Chi-Square Test, ${ }^{\mathrm{c}}$ only 24 patients had family members, who were caregivers and consented participation at the study 
Table 3 Characteristics of patients with recommendation for social work intervention $(n=53)$

\begin{tabular}{llll}
\hline Social work intervention recommended: & NO & YES & $p$-values \\
\hline Age (mean (SD)) & $71(9)(n=32)$ & $69(11)(n=21)$ & $0.443^{a}$ \\
Male, $n(\%)$ & $16(50 \%)(n=32)$ & $13(62 \%)(n=21)$ & $0.394^{\text {b }}$ \\
Modified Rankin Scale (mRS) median (IQR) & $1(1-3)(n=32)$ & $3(2-3)(n=21)$ & $0.013^{\text {a }}$ \\
Nikolaus-score median (IQR) & $21(19-22)(n=32)$ & $17(15-21)(n=21)$ & $0.005^{a}$ \\
Stroke-Impact-Scale median (IQR) & $34(27-40)(n=32)$ & $24(21-33)(n=21)$ & $0.014^{a}$ \\
EQ-5D-5 L-Index median (IQR) & $0.89(0.79-1.0)(n=32)$ & $0.79(0.70-0.89)(n=21)$ & $0.060^{{ }^{a}}$
\end{tabular}

${ }^{\mathrm{a}}$ Mann-Whitney-U Test, ${ }^{\mathrm{b}}$ Chi-Square Test

being overwhelmed with information or impaired cognition [35]. Stroke patients are prone to reporting bias concerning services received [36]. Ten patients of the presented study, who received rehabilitation, reported no contact with social workers. In Germany, application for rehabilitation is usually connected to a social work intervention, so these ten patients were not aware of the social support they received. On the other hand, they may not have understood this support as social support, and would perhaps have required more support in other domains e.g. preparation for their return to home. Therefore, the social work service - especially in the acute - phase should be adapted to the patient's situation. This would mean a proper introduction of the consulting social worker, enough time and adapting the information load to the patient's cognitive abilities.

The data demonstrate that most of the social worker contact takes place during the stay in hospital or rehabilitation. Unfortunately, our questionnaire did not differ between social support in hospital and rehabilitation. In the acute phase, hospital social support usually assists in applying for rehabilitation. In the second phase, social support assists in discharge, aiming to organize nursing services for severely affected patients. For this reason, less affected patients did not receive as much social consultation. Even if there was no need for rehabilitation or nursing services, unmet social needs remain; e.g. getting advice on how to obtain benefits, information on driving after stroke, contact details of medical doctors and self-help groups, help with arranging housekeeping and dealing with the disability in the context of relationships and sexuality [34, 37-39]. Patients need social work services to begin early in acute treatment and continue after discharge [40]. Our data indicates that unfortunately there was scarce social support after discharge in the long-term. Services like the outpatient stroke service point in Berlin [34] may provide a model to address this problem. The role of social workers is crucial, serving to liaise between different institutions in order to assist patients. In our opinion, this role does not receive adequate recognition. More research in this field would emphasize the importance of post-acute stroke services [41]. Evaluating the effect of social worker interventions is part of our consecutive MAS-II study (Managing Aftercare for Stroke - A Longitudinal Complexinterventional Study in Post-rehabilitation Stroke Patients, clinicaltrials.gov NCT03097146).

Our data suggests that previous social worker contact does not reduce social needs in the aftercare (described by the patients themselves as well as evaluated by the neurologist). This might be because initial social worker contact is mainly in hospital, and rehabilitation takes place to organize rehabilitation and nursing home care in more severely affected patients. Independent of the severity of their stroke, patients in the long-term have unmet (or yet to be identified) social needs that have not been covered by their previous contact with a social worker. This emphasizes that in the years after stroke, health care providers should regularly screen for unmet social needs. Over $50 \%$ of patients and their relatives visit social services $>6$ months after the initial event. This takes place when patients have returned home or to a nursing home, adaption to this new everyday life has happened and unmet needs are discovered (Cameron \& Gignac, 2008) [34]. Our data demonstrates

Table 4 Modified Rankin Scale (mRS): Unmet needs (Nikolaus-Score) and recommendation for social work intervention $(n=57)$

\begin{tabular}{llll}
\hline & $m R S<3$ (low-moderate degree of disability) $(n=34)$ & $m R S>2$ (severe degree of disability) $(n=23)$ & $p$-value \\
\hline Age (mean (SD)) & $71(9)(n=33)$ & $69(11)(n=22)$ & $0.491^{\text {a }}$ \\
Male, $n(\%)$ & $22(65 \%)(n=33)$ & $11^{(48 \%)(n=23)}$ & $0.205^{b}$ \\
Nikolaus-score median (IQR) & $21^{\mathrm{b}}(19-22)(n=34)$ & $19(15-20)(n=23)$ & $0.013^{\text {a }}$ \\
$\begin{array}{l}\text { Social work intervention recommended } \\
(n=21 / 53), n(\%)\end{array}$ & $9(28 \%)(n=32)$ & $12(57 \%)(n=21)$ & $0.035^{b}$ \\
\hline
\end{tabular}

${ }^{\mathrm{a}}$ Mann-Whitney-U Test, ${ }^{\mathrm{b}}$ Chi-Square Test 
Table 5 Contact with social workers $(n=57)$

\begin{tabular}{llll}
\hline & Never had contact with social worker $(n=17)$ & Had contact with social worker $(n=40)$ & $p$-value \\
\hline Age (mean (SD)) & $71(12)(n=17)$ & $70(9)(n=38)$ & $0.247^{\text {a }}$ \\
Male, $n(\%)$ & $12(70 \%)(n=17)$ & $21(53 \%)(n=40)$ & $0.251^{\text {b }}$ \\
Modified Rankin Scale (mRS) median (IQR) & $1(1-3)(n=17)$ & $2(1-3)(n=40)$ & $0.058^{\text {a }}$ \\
Years of education Median (IQR) & $16(12-19)(n=17)$ & $14(12-16)(n=39)$ & $2050(913-2650)(n=32)$ \\
Net income in Euro median (IQR) & $2250(1300-2500)(n=15)$ & $20(17-21)(n=40)$ & $0.352^{\text {a }}$ \\
Nikolaus-score median (IQR) & $21(17-22)(n=17)$ & $7(18 \%)(n=40)$ & $0.714^{\text {a }}$ \\
Nikolaus-score $<17$ Points $n(\%)$ & $3(18 \%)(n=17)$ & $16(43 \%)(n=37)$ & $0.983^{\text {a }}$ \\
Social work intervention recommended $n(\%)$ & $5(31 \%)(n=16)$ & & $0.412^{\text {b }}$ \\
\hline
\end{tabular}

${ }^{\mathrm{a}}$ Mann-Whitney-U Test, ${ }^{\mathrm{b}}$ Chi-Square Test

that patients with unmet needs evaluated by the Nikolaus-Score in the long-term were more severely affected and had a lower income. Furthermore, they have a lower quality of life and a higher caregiver burden. Caregivers often experience stress and poor mental and physical health [42], which can lead to poor rehabilitation outcome of stroke survivors [43, 44].

In the MAS-I study several patients received a recommendation for social work intervention by the stroke neurologist, but were not classified by the Nikolausscore as being in need of social help. In terms of methods, an internationally validated screening tool for social needs after stroke is still required. The Nikolausscore is widely used in Germany, but does not seem to be an appropriate up-to-date tool. First, it is not specifically validated for stroke patients, but for a general geriatric population [26]. Second, the items regarding the housing situation are outdated: warm water, heating, toilets or telephone sockets are basic standards nowadays, but are weighted as important items in the score, falsely increasing the score. Third, the Nikolausscore combines items like "apartment on one floor, spacious and wheelchair accessible" which aggregates complex accessibility issues. Fourth, these items might not be relevant if the stroke patient is not wheelchair bound, but the score-point counts nevertheless. The recommendations for social work intervention made by the clinician included the results of the Nikolaus-score but also took into consideration information given by the patient during the interview, which our social worker had not asked about in the standardized questionnaires. Furthermore, we considered 14 of the 40 items of the Stroke Survivor Needs questionnaire, which were seen as relevant for addressing social issues. Twenty-four patients were not referred to a social worker although showing needs in these components of the Stroke Survivor Needs questionnaire. These needs are not currently covered under the legal entitlements in Germany, unless individual preconditions have been fulfilled and some elements of care may not be covered by personal care insurance.
It would be desirable to develop an evaluation tool for social needs considering personal contextual factors of the ICF (International Classification of Functioning). This includes relevant personal factors to describe the background of an individual's life and living [45]. Moreover, such a questionnaire should focus on contemporary topics relevant for stroke patients, such as inpatient and outpatient rehabilitation, medical treatment, medical rehabilitation, therapeutic or preventive services, questions around medical and personal care insurance, social legislation, pensions and disability benefits and information on self-help groups [34]. Not only should the unmet needs be evaluated, but also the legal preconditions based on which social benefits can be applied for. A literature review shows that longer-term problems of stroke patients concern social and emotional consequences $[25,46]$. Even mildly affected patients seek psychological support as anxiety after stroke is common $[47,48]$. The emotional as well as the social situation should be recorded since multiple studies reveal an association between depression and low-social support [49].

Relatives of stroke patients play an essential role in providing care. It is important to include the caregivers` situation in the evaluation. So far there is no standardized procedure in Germany of when to provide support to caregivers concerning follow-up care for patients [50], even though many suffer from psychological and physical stress [51]. Two-thirds of the clients contacting stroke service points in Berlin are caregivers [34]; this

Table 6 Content and quality of social support

\begin{tabular}{lll}
\hline & $\mathrm{n}(\%)$ & Total $\mathrm{n}$ \\
\hline $\begin{array}{l}\text { Provided with detailed information } \\
\text { about the situation }\end{array}$ & $14(39 \%)$ & 36 \\
$\begin{array}{l}\text { Provided with a leaflet/flyer or brief } \\
\text { information material }\end{array}$ & $20(54 \%)$ & 37 \\
$\begin{array}{l}\text { Information about items such as rehabilitation, } \\
\text { nursery care, benefits and social rights }\end{array}$ & $9(25 \%)$ & 36 \\
$\begin{array}{l}\text { Help to fill out application forms } \\
\text { Long-term support after discharge }\end{array}$ & $12(33 \%)$ & 36 \\
\hline
\end{tabular}


reveals the need to involve the nearest relative in evaluation and support. In the MAS-I study $24 \%$ of the caregivers reported moderate to high levels of stroke-related caregiver burden [11].

Several approaches have been suggested to close the gap between inpatient and outpatient care [52-54], however, social care has been understudied. An effective primary care-based stroke aftercare service must have a broad focus and must be based on an individual record of unmet needs including social needs [55]. Thus far, in the out-patient setting it is difficult to record unmet needs after stroke appropriately. Similar levels of impairment can impact individuals differently, depending on the context. Also the individual resources like personality and caregiver's support to deal with long-term complications are very different [56] and can lead to comorbidities like depression as well as a low quality of life [57]. Patients who receive little information about their situation are more likely to be depressed [58]. Low socioeconomic status increases the risk for stroke [58]. Socially isolated stroke patients are more likely to have recurrent stroke and have a higher mortality [59]. Social needs require to be identified to be treated.

Due to a rather small sample size and the fact that severely disabled patients and their carers were less likely to attend, we advise caution when interpreting these findings. On the other hand, a strength of the studied population is its detailed characterization, which allows for exploratory analysis.

\section{Conclusions}

In the present study we see that only two thirds of stroke patients have contact with social workers. This contact mainly takes place during the in-patient setting. Although they may have had social worker contact previously, patients continue to have unmet needs for longterm aftercare. Forty percent of all patients included in the MAS-I study received the recommendation for social work intervention after an in-depth analysis of their situation. Our data suggest that screening tools for unmet social needs as the Nikolaus-score are not appropriate to report the needs holistically. Finally, we saw that unmet social needs were associated with lower quality of life and higher care giver burden.

The findings warrant large prospective, longitudinal studies identifying and validating screening tools for unmet social needs and to develop comprehensive management of unmet social needs to improve medical and social outcomes in stroke.

\section{Additional files}

Additional file 1: Cross table: Prevalence and time of contact with social worker ( $n=56,1$ missing). This file shows in a cross table the numbers and percentages of patients who have or have not had contact with social workers during and/or after stay in hospital or rehabilitation. The McNemar Test shows a significant result $(p<0.001)$. (DOCX $13 \mathrm{~kb}$ )

Additional file 2: English version of the Nikolaus Score [26] translated by the authors. We explicitly declare that this is neither an official nor a verified translation. (DOCX $20 \mathrm{~kb}$ )

\section{Abbreviations}

HPS-k: Häusliche Pflegeskala; ICF: International Classification of Functioning; IQR: Interquartile range; MAS: Managing aftercare of stroke (study); mRS: modified Rankin Scale; n: number

\section{Acknowledgements}

The authors acknowledge the consulting contributions by Prof. Dr. Claudia Wendel and Gisela Kiank, the contribution of members of the CSB's stroke research consumers group.

(SBHF) group. We acknowledge support from the German Research Foundation (DFG) and the Open Access Publication Funds of Charité Universitätsmedizin Berlin.

\section{Authors' contributions}

SL: drafted and wrote the manuscript, performed data interpretation and analysis. BH: study implementation, data collection, help with data interpretation and manuscript preparation. IP: data collection, help with data interpretation and manuscript preparation. PK: study implementation, data collection, help with data interpretation and manuscript preparation. DR: help with data interpretation and manuscript preparation. AL: data collection, help with data interpretation and manuscript preparation. UG: help with data interpretation and manuscript preparation. IW: help with data interpretation and preparation of the manuscript. AM: obtaining funding, study concept, study design and preparation of the manuscript. All authors read and approved the final manuscript.

\section{Funding}

The author(s) disclosed receipt of the following financial support for the research, authorship, and/or publication of this article: This study was supported by German Federal Ministry of Education and Research (01EO0801) and German Research Foundation (Exc257). Funding was granted based on the initial study design, but the funding bodies had no involvement in the conception of the study or any of the subsequent work.

\section{Availability of data and materials}

The datasets used and/or analysed during the current study are available from the corresponding author on reasonable request.

\section{Ethics approval and consent to participate}

This study received ethics approval by the institutional ethics committee of Charité University Medicine Berlin (reference EA1/183/14). All participants gave informed written consent either themselves or via a legal representative. In this case the patients haven't been able due to their motoric or cognitive limitations to sign for themselves. The legal representative was installed before participation in the study by the primary treating physicians in accordance with the legal requirements and was able to prove this with a legal document.

\section{Consent for publication}

Not applicable.

\section{Competing interests}

Author Andreas Meisel is an editorial board member of BMC Neurology.

\section{Author details}

${ }^{1}$ Center for Stroke Research Berlin, Charité University Medicine Berlin, Charitéplatz 1, 10117 Berlin, Germany. ²Department of Neurology, Charité University Medicine Berlin, Charitéplatz 1, 10117 Berlin, Germany. ${ }^{3}$ NeuroCure Clinical Research Center, Charité University Medicine Berlin, Charitéplatz 1, 10117 Berlin, Germany. ${ }^{4}$ Clinical Epidemiology and Health Services in Stroke, Charité University Medicine Berlin, Charitéplatz 1, 10117 Berlin, Germany. ${ }^{5}$ Berlin Stroke Alliance (BSA), Charitéplatz 1, 10117 Berlin, Germany. Institute of Biometry and Clinical Epidemiology, Charité University Medicine Berlin, Charitéplatz 1, 10117 Berlin, Germany. ${ }^{7}$ Berlin Institute of Health (BIH), 
Anna-Louisa-Karsch 2, 10178 Berlin, Germany. ${ }^{8}$ Department of Public Health and Primary Care, Cambridge Institute of Public Health, University of Cambridge, Cambridge CB2 OSR, UK.

Received: 1 March 2019 Accepted: 27 August 2019

Published online: 06 September 2019

\section{References}

1. World Health Organization. The world health report 2002. Midwifery. 2003; 19:72-3.

2. Feigin VL, Norrving B, Mensah GA. Global burden of stroke. Circ Res. 2017; 120(03):439-48.

3. Feigin $\mathrm{VL}$, et al. Update on the global burden of ischemic and hemorrhagic stroke in 1990-2013: the GBD 2013 study. Neuroepidemiology. 2015;45(03): 161-76.

4. Siegel J, Edwards E, Mooney L, et al. A feasibility pilot using a mobile personal health assistant (PHA) app to assist stroke patient and caregiver communication after hospital discharge. Mhealth. 2016;(2):31.

5. Ellis G, Mant J, Langhorne P, et al. Stroke liaison workers for stroke patients and carers: an individual patient data meta-analysis. Cochrane Database Syst Rev; 2010. p. CD005066.

6. Fearon P, Langhorne P. Early supported discharge Trialists. Services for reducing duration of hospital care for acute stroke patients. Cochrane Database Syst Rev; 2012. p. CD000443.

7. Fisher RJ, Gaynor C, Kerr M, et al. A consensus on stroke: early supported discharge; 2011. p. 1392-7.

8. Summers D, Leonard A, Wentworth D, et al. Comprehensive overview of nursing and interdisciplinary care of the acute ischemic stroke patient: a scientific statement from the American Heart Association. Stroke. 2009;40: 2911-44.

9. Schwamm LH, Pancioli A, Acker JE, et al. Recommendations for the establishment of stroke systems of care: recommendations from the American Stroke Association's task force on the development of Stroke systems. Stroke. 2005;36:690-703.

10. Winstein Cl, Stein J, Arena R, et al. Guidelines for adult Stroke rehabilitation and recovery: a guideline for healthcare professionals from the American Heart Association/American Stroke Association. Stroke. 2016:47:e98-16.

11. Hotter B, Liebenau A, Knispel P, Heel S, Steube D, Wissel J, Wellwood I, Meisel A. Identifying unmet needs in long-term stroke care using indepth assessment and the post-Stroke-checklist - the managing aftercare for Stroke (MAS-I) study. European Stroke Journal. 2018.

12. Dewan $B$, et al. A service evaluation of the feasibility of a communitybased consultant and stroke navigator review of health and social care needs in stroke survivors 6 weeks after hospital discharge. Clin Med. 2014;14(2):123-40.

13. Wray F, Clarke D, Forster A. Post-stroke self-management interventions: a systematic review of effectiveness and investigation of the inclusion of stroke survivors with aphasia. Disabil Rehabil. 2018;40(11):1237-51.

14. Kumar S, Selim MH, Caplan LR. Medical complications after stroke. Lancet Neurol. 2010;9:105-18

15. Godecke E, Ciccone NA, Granger AS, Rai T, West D, Cream A, Cartwright J, Hankey GJ. A comparison of aphasia therapy outcomes before and after a very early rehabilitation programme following stroke. Int J Lang Commun Disord. 2014;49(2):149-61.

16. Wissel J, Verrier M, Simpson DM, Charles D, Guinto P, Papapetropoulos S, Sunnerhagen KS. Post-stroke spasticity: predictors of early development and considerations for therapeutic intervention. PM R. 2015;7(1):60-7.

17. Delpont B, Blanc C, Osseby GV, Hervieu-Bègue M, Giroud M, Béjot Y. Pain after stroke: A review. Rev Neurol. S0035-3787(17)30658-6.

18. Watila MM, Balarabe SA. Factors predicting post-stroke aphasia recovery. J Neurol Sci. 2015;352(1-2):12-8.

19. Nabavi SF, Turner A, Dean O, Sureda A, Mohammad S. Post-stroke depression therapy: where are we now? Curr Neurovasc Res. 2014;11(3): 279-89.

20. Rogers JM, Foord R, Stolwyk RJ, Wong D, Wilson PH. General and domainspecific effectiveness of cognitive remediation after Stroke: systematic literature review and meta-analysis. Neuropsychol Rev. 2018. Epub ahead of print.

21. Wang YC, Kapellusch J, Garg A. Important factors influencing the return to work after stroke. Work. 2014;47(4):553-9.
22. Cooper CL, Phillips LH, Johnston M, Whyte M, MacLeod MJ. The role of emotion regulation on social participation following stroke. $\mathrm{Br} J$ Clin Psychol. 2015;54(2):181-99.

23. Haun J, Rittmann M, Sberna M. The continuum of connectedness and social isolation. J Aging Stud. 2008;22:54-69.

24. Stroke Alliance for Europe. The burden of stroke in Europe. 2017.

25. Pindus DM, et al. Stroke survivors' and informal caregivers' experiences of primary care and community healthcare services - a systematic review and meta-ethnography. PLoS One. 2018;13(2):e0192533.

26. Nikolaus T, Specht-Leible N, Bach M, Oster P, Schlierf G. Social aspects in diagnosis and therapy of very elderly patients. Initial experiences with a newly developed questionnaire within the scope of geriatric assessment (Article in German). Z Gerontol. 1994:27(4):240-5.

27. McKevitt C, Fudge N, Redfern J, Sheldenkar A, Crichton S, Rudd AR, Forster A, Young J, Nazareth I, Silver LE, Rothwell PM, Wolfe CDA. Self-reported long-term needs after stroke. Stroke. 2011;42:1398-403.

28. Greiner W, Claes C, JJV B. Validating the EQ-5D with time trade off for the German population. Eur J Health Econ, pp. 2005;6(2):124-30.

29. Graessel E, Berth H, Lichte T, Grau H. Subjective caregiver burden: validity of the 10-item short version of the Burden Scale for Family Caregivers BSFC-s. BMX Geriatr. 2014:14:23.

30. Banks JL, Marotta CA. Outcomes validity and reliability of the modified Rankin scale: implications for stroke clinical trials: a literature review and synthesis. Stroke. 2007;38(3):1091-6.

31. Duncan PW, Wallace D, Lai SM, Johnson D, Embretson S, Laster LJ. The stroke impact scale version 2.0. Evaluation of reliability, validity, and sensitivity to change. Stroke. 1999;30(10):2131-40.

32. https://www.schlaganfallcentrum.de/en/patient-information/stroke-servicepoint/.

33. Rowe JM, et al. The role of social workers in addressing nonmedical needsin primary health care. Soc Work Health Care. 2017:56(6):435-49.

34. Padberg I, et al. Social work after stroke: identifying demand for support by recording stroke patients' and carers' needs in different phases after stroke. BMC Neurol. 2016;16:111

35. Ferro JM. Hyperacute cognitive stroke syndromes. J Neurol. 2001;248(10):841-9.

36. Luther A, Lincoln NB, Grant F. Reliability of stroke patients' reports on rehabilitation services received. Clin Rehabil. 1998;12(3):238-44.

37. Seymour LM, Wolf TJ. Participation Changes in Sexual Functioning after Mild Stroke. OTJR (Thorofare N J). 2014:34(2):72-80.

38. Tamam $Y$, et al. Post-stroke sexual functioning in first stroke patients. Eur J Neurol. 2008;15(7):660-6.

39. McGilton KS, Vellani S, et al. Identifying and understanding the health and social care needs of older adults with multiple chronic conditions and their caregivers: a scoping review. BMC Geriatrics. 2018;18:231.

40. Linton KF, et al. From Discharge Planner to "Concierge": Recommendations for Hospital Social Work by Clients with Intracerebral Hemorrhage. Soc Work Public Health. 2014;(6):486-95.

41. Duncan PW, et al. The comprehensive post-acute stroke services (COMPASS) study: design and methods for a cluster randomized pragmatic trial. BMC Neurology. 2017:17:133.

42. Han B and Haley WE. Family caregiving for patients with stroke. 1999 Stroke, pp. 14:1478-1485.

43. Evans RL, Bishop DS, Haselkorn JK. Factors predicting satisfactory home care after stroke. Arch Phys Med Rehabil, pp. 1991:14:144-7.

44. Jill C, et al. Randomized clinical trial of the timing it right stroke family support program: research protocol. BMC Health Serv Res, p. 2014:14:18,

45. Grotkamp S, et al. Personal contextual factors of the ICF draft from the Working Group "ICF" of Specialty Group II of the Geman Society for Social Medicine and Prevention. Gesundheitswesen. 2010;72(12):908-16.

46. Murray J, et al. Developing a primary care-based stroke service: a review of the qualitative literature. Br J Gen Pract. 2003:53(487):137-42.

47. Chun HY, et al. Anxiety After Stroke: The Importance of Subtyping. Stroke. 2018:49(3):556-64

48. White $\mathrm{CL}$, Barrientos R, Dunn K. Dimensions of uncertainty after stroke: perspectives of the stroke survivor and family caregiver. J Neurosci Nurs. 2014;46(4):233-40

49. Hackett ML, and Anderson CS. Predictors of depression after stroke. A systematic review of observational studies. 2005, pp. 36:2296-2301.

50. Schlote A, et al. Knowledge of support and aid after first stroke. Rehabilitation (Stuttg). 2008;47(3):136-44.

51. Camak DJ. Addressing the burden of stroke caregivers: a literature review. Clin Nurs. 2015;24(17-18):2376-82. 
52. Hempler I, et al. Post-stroke care after medical rehabilitation in Germany: a systematic literature review of the current provision of stroke patients. BMC Health Serv Res. 2018;18:468.

53. Barlinn J, et al. Organized Post-Stroke Care through Case Management on the Basis of a Standardized Treatment Pathway : Results of a Single-Centre Pilot Study. 2016, Nervenarzt, pp. 87(8):860-869.

54. Reeves $\mathbf{M}$, et al. Improving transitions in acute stroke patients discharged to home: the Michigan stroke transitions trial (MISTT) protocol. BMC Neurol. 2017;17:115

55. Murray J, et al. Developing a primary care-based stroke model: the prevalence of longer-term problems experienced by patients and carers. $\mathrm{Br}$ J Gen Pract. 2003;53(495):803-7

56. Ch'ng AM, French D, McLean N. Coping with the challenges of recovery from stroke: long term perspectives of stroke support group members. J Health Psychol. 2008;13(8):1136-46.

57. Barker-Collo SL. Depression and anxiety 3 months post stroke: prevalence and correlates. Arch Clin Neuropsychol. 2007:22(4):519-31.

58. Baumann M, Le Bihan E, Chau K, Chau N. Associations between quality of life and socioeconomic factors, functional impairments and dissatisfaction with received information and home-care services among survivors living at home two years after stroke onset. BMC Neurol. 2014;14:92.

59. Ayerbe L, Ayis S, Rudd AG, Heuschmann PU, Wolfe CD. Natural history, predictors, and associations of depression 5 years after stroke: the South London Stroke Register. Stroke. 2011;42(7):1907-11.

\section{Publisher's Note}

Springer Nature remains neutral with regard to jurisdictional claims in published maps and institutional affiliations.

Ready to submit your research? Choose BMC and benefit from:

- fast, convenient online submission

- thorough peer review by experienced researchers in your field

- rapid publication on acceptance

- support for research data, including large and complex data types

- gold Open Access which fosters wider collaboration and increased citations

- maximum visibility for your research: over $100 \mathrm{M}$ website views per year

At BMC, research is always in progress.

Learn more biomedcentral.com/submissions 